\title{
HIGH-SPEED VIDEOS OF LABORATORY LEADERS EMERGING FROM WIND TURBINE BLADE TIPS
}

\author{
J. Montanyà ${ }^{1}$, V. March ${ }^{1}$, B. Hermoso ${ }^{2}$ and J.R. Hermoso ${ }^{1}$ \\ ${ }^{1}$ Electrical Engineering Department, Technological University of Catalonia, Terrassa (Barcelona), Spain \\ ${ }^{2}$ Electrical Engineering Department, Public University of Navarre, Pamplona, Spain
}

\begin{abstract}
This paper presents some observation results of the attachment test of a wind turbine blade as described in the upgrade of the IEC-61400-24. The optical observations were performed by means of high-speed video and UV-sensitive photo camera. This study investigates the effects on the leaders emerging from the blade comparing three different air-terminals: discrete receptors, discrete receptors with diverter strips and metallic tip. In the first two types, salt mist pollution was applied to the blade. For non polluted tips positive leaders appeared from receptors towards the ground avoiding the blade surface. When the blade was polluted additional leaders emerged moving horizontally. Moreover, in this situation the leader progressed on the blade surface. Pollution also produced the inception of more leaders when the blade was equipped with discrete receptors and diverter strips.
\end{abstract}

Rotor blades are the most exposed parts to lightning of a wind turbine. Due to the recent increase in power per wind generator, blades are becoming longer and the entire turbine higher. New materials such carbon reinforced plastics (CRP) are more commonly used within blades. The increase in complexity of rotor blades get complexity protect against lightning. Most blade manufactures base their lightning protection with simple receptors distributed along the blade surface. However this solution complicates the protection of sensitive components to direct lightning as structural CRP. In order to address the lightning protection of wind turbines and its blades, the international technical report IEC TR61400-24[1] has been recently upgraded [2]. The new document addresses precisely the tests to conduct to rotor blades in order to investigate the performance of their lightning protection system. These tests may be classified as attachment tests and current conduction tests. The first ones seek to investigate the probable locations in a blade where the lightning can attach while the second ones are used to demonstrate the lightning current conduction capabilities of all the lightning protection system. Lightning attachment tests are executed by means of hanging the blade above a conductive ground in different positions and energize with voltage impulses in order to produce streamers, leaders and breakdowns from the blade towards the ground. During the tests images of the leader attachment and inception points must be pictured or recorded.

By the way, published tests results [3] show the strong difference between the leader interactions with the blade according the polarity of the discharge. Results shows how positive leaders emerging from receptors tend to propagate in air while negative leaders like to leave the blade by its surface.

Several papers deal with high voltage laboratory test of wind turbine blades (e.g.[4-6]) studying the attachment manner of lightning and evaluating the damage mechanism. As result, major damages are produced when the discharge penetrates inside the blade. The overpressure caused by the lightning channel inside and the possible interaction with water generates, perhaps the most dramatic effects. Among the publications related to laboratory test only few consider the effect of 'pollution' such as water (e.g. [7-10]).

In this paper we present high-speed video recordings of blade attachment tests. The results correspond to three different configurations of receptors: discrete receptors, discrete receptors with diverter strips and metallic tip. To investigate the effect of pollution the blade was sprayed with salt mist for the first two types of terminals. The objective here is not to present a complete test according to the mentioned standard (since not all blade positions were tested) if not is to show the different behavior of the three different receptors.

\section{TEST SETUP}

The test setup corresponds to the type A described in the upgraded version of the IEC 61400-24 [2]. As shown in figure 1a, a $5 \mathrm{~m}$ blade section was hanging horizontally above the conducting ground. The lightning protection system was connected to a high voltage marx generator. The selected waveform shape was switching impulse, as recommended, in order to let stramers and leaders develop thanks to its slow rise time. 


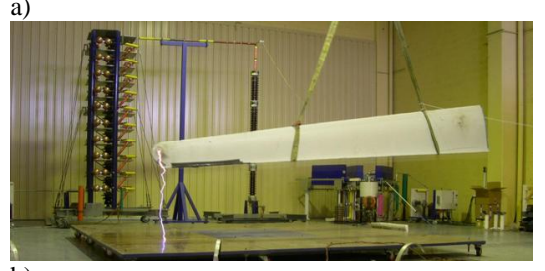

b)

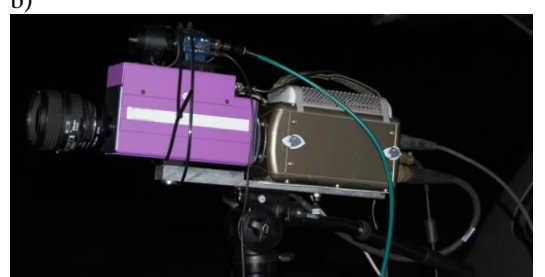

Figure 1. a) Test setup and; b) High-speed video system.

Videos of leader progression were recorded by means of the high-speed camera (figure 1b). The camera allows recording videos at 6814 frames per second (fps) at full resolution $(800 \times 600$ pixels) up to $500000 \mathrm{fps}$ at $32 \times 32$ pixels. In the present study we used video frame rates up to $93000 \mathrm{fps}$. Additional to high-speed videos, a modified photo camera for UV range was also employed. This camera allows remote triggering that allows to place at distances close to the blade.

\section{GENERAL CHARACTERISTICS OF OBSERVATIONS}

\subsection{Discrete tip receptors}

Keeping the blade non-polluted, positive leaders emerge clearly from the receptor towards de ground avoiding the blade surface (figure $2 \mathrm{a}$ ). a)

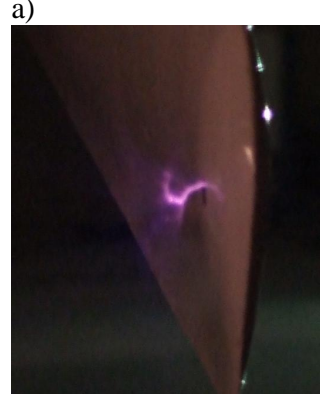

b)

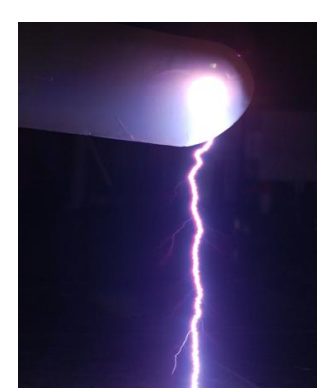

Figure 2. a) Picture of an emerging leader from the non polluted blade tip receptor and; b) picture of the breakdown where not side streamers or leaders are observed.

After testing with the dry blade, salt mist was sprayed avoiding up to $30 \mathrm{~cm}$ of the tip (as indicated in figure $3 \mathrm{a}$ ). Since the salt mist was applied, we observed the apparition of a lateral leaders developing before the inception of the leaders to the ground (figure $3 b$ ).
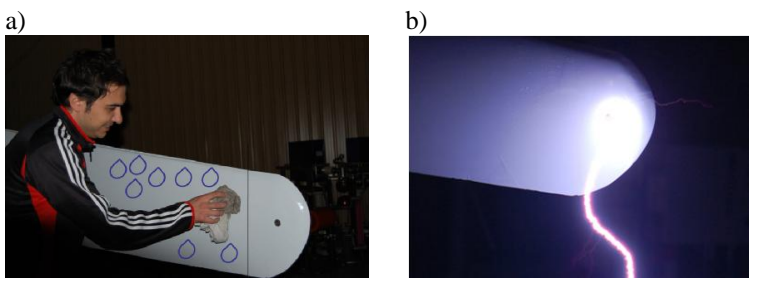

Figure 3. a) Picture representing the area where salt mist was applied and; b) picture of the breakdown where a side streamers is observed.

Figure 4 shows the leader progression at different times of the breakdown showed in figure $3 \mathrm{~b}$. In the first four frames $(38 \mu \mathrm{s})$ it is possible to observe how the initial leader tends to propagate to the left side of the blade receptor. This phenomenon was not observed when the blade was non-polluted.
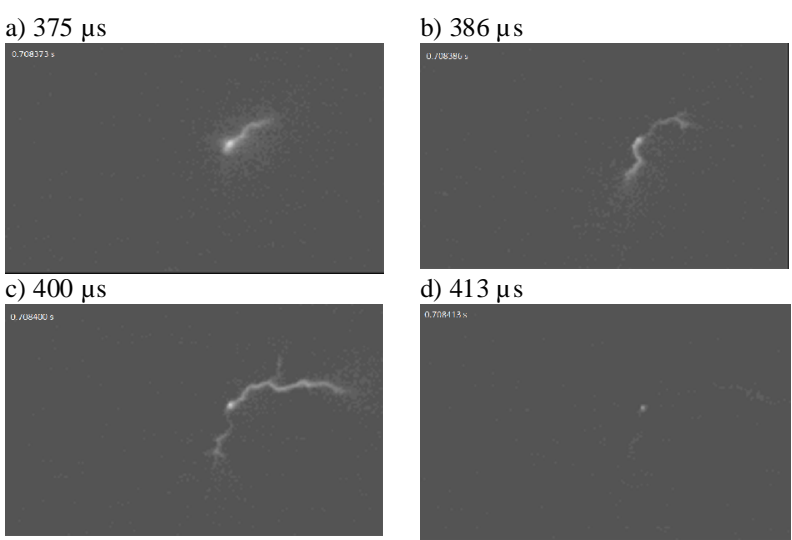

\section{d) $413 \mu \mathrm{s}$}

e) $427 \mu \mathrm{s}$
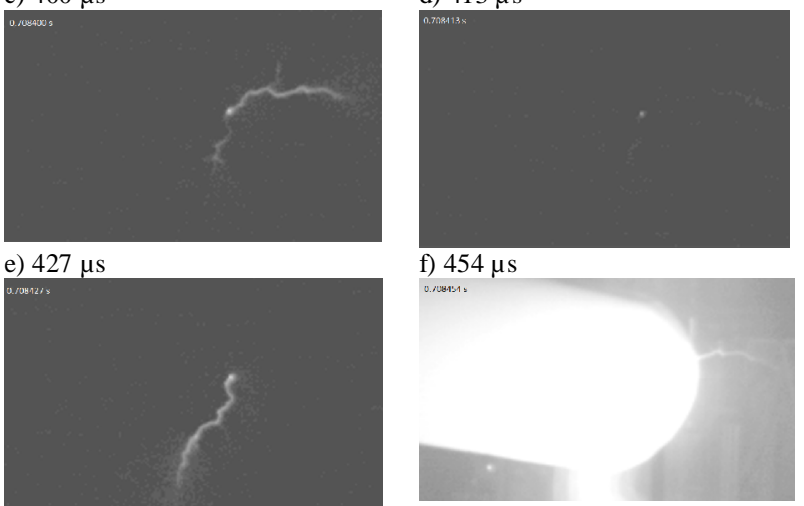

Figure 4. Sequence of video frames corresponding to the leader process in the discharge of figure $3 \mathrm{~b}$.

As the salt mist approached the tip zone of the blade the initial side leader reached longer distances. Once the blade was full polluted, still lateral leaders appeared. We observed faster propagation of the leaders thanks to the effect of the droplets on the surface (figure 5). 


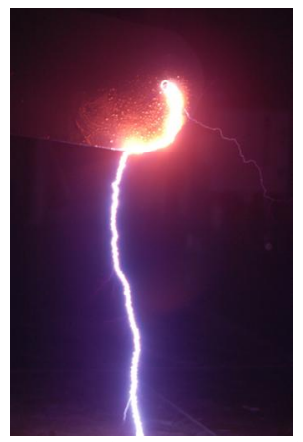

Figure 5. Picture of the breakdown when the blade is full polluted with salt mist.

\subsection{Discrete tip receptors with diverter strips}

A $30 \mathrm{~cm}$ diverter strip from the tip receptor to the trailing edge of the blade was installed. The diverter was a commercial brand commonly used in aircraft. With the diverter, we first tested its behavior without breakdown to ground for both positive and negative polarities. Figure 6 displays two pictures for a non polluted blade. Note how in both polarities the diverter elements are shortcircuited by the discharge. The emerging leaders have different behavior. While in the negative polarity small leaders appear just at the end of the diverter, in the positive polarity longer leaders emerge from the end of the diverter as well from other intermediate sections (figure 6a) probably due to irregularities of the diverter. As occurred with discrete terminals, positive leaders tend to avoid blade surface when this is non polluted. a)

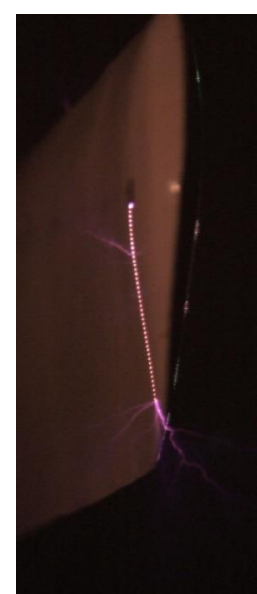

b)

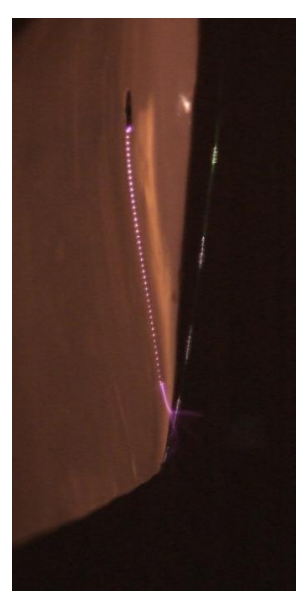

Figure 6. Energization of the blade with diverter strips with (a) positive polarity and (b) negative polarity.

Pictures in figure 6 provide a static image of the performance of the diverter. By means of high-speed video we found that, in both cases, the breakdown of the diverter (between diverter elements) was flashing in different manner. The voltage level for both polarities was equal. With positive polarity, the diverter was initially breakdown in $11 \mu \mathrm{s}$. The breakdown kept for $130 \mu \mathrm{s}$ while the leaders developed. After, the breakdown started to flash. The case of negative polarity, the diverter required $22 \mu \mathrm{s}$ to breakdown but it flashed all the time with a period of $22 \mu \mathrm{s}$. This effect would be due to the nature of the leader propagation with different polarities. However, in both polarities the diverter triggered and no other leaders emerging from other parts (for non polluted blade).

By increasing voltage, the breakdown of the blade towards the ground occurred. Breakdown of the blade without pollution is presented in figure 7 . Note how the leaders emerge from the diverter end to the ground (figure $7 \mathrm{a}$ to $7 \mathrm{~h}$ ). In this case no other leaders were observed from the blade. The same case is displayed in figure 8 but, at that time, the blade was polluted with salt mist. The figure shows the effect of pollution in the development of the leader. Due to the pollution, during the leader phase of the discharge the diverter was not full breakdown (e.g. figure 8a). This may be due to that some elements of the diverter were already 'short-circuited' by the applied pollution. Another observed effect is the apparition of leaders extending in other directions through the blade surface. Once the blade was polluted a leader upwards from the tip receptor appeared (figure $8 \mathrm{~d}$ to $8 \mathrm{~g}$ ).

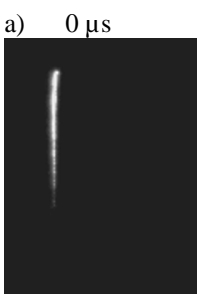

d) $39 \mu \mathrm{s}$

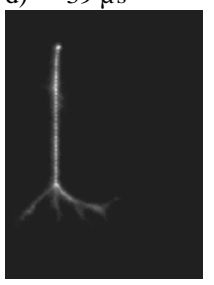

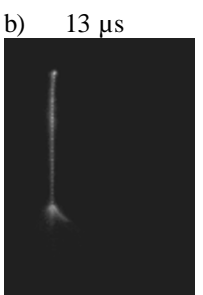

f) $52 \mu \mathrm{s}$
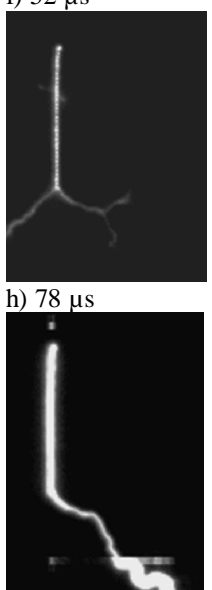

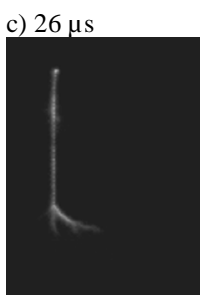

g) $65 \mu \mathrm{s}$

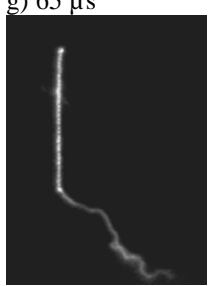

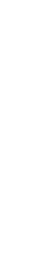

Figure 7. Leader process in a positive breakdown of a non polluted blade with diverter strips.

As resume, when the blade was polluted with salt mist we observed the inception of more leaders and in 
different directions, even upward leaders from the receptors appeared. During all the impulses the blade rested horizontally. In all the impulses the breakdown followed the diverter.

\subsection{Metallic tip}

In order to have a metallic tip, in our experimental blade we glued aluminum foil (figure 9). With this configuration we tested several positions (inclinations) investigating the evolution of the emerging leaders. With the conductive tip, the blade was not submitted to salt mist. In this case we were more interested on the investigation about how leaders incept from the tip and the effects of the blade inclination respect the ground.
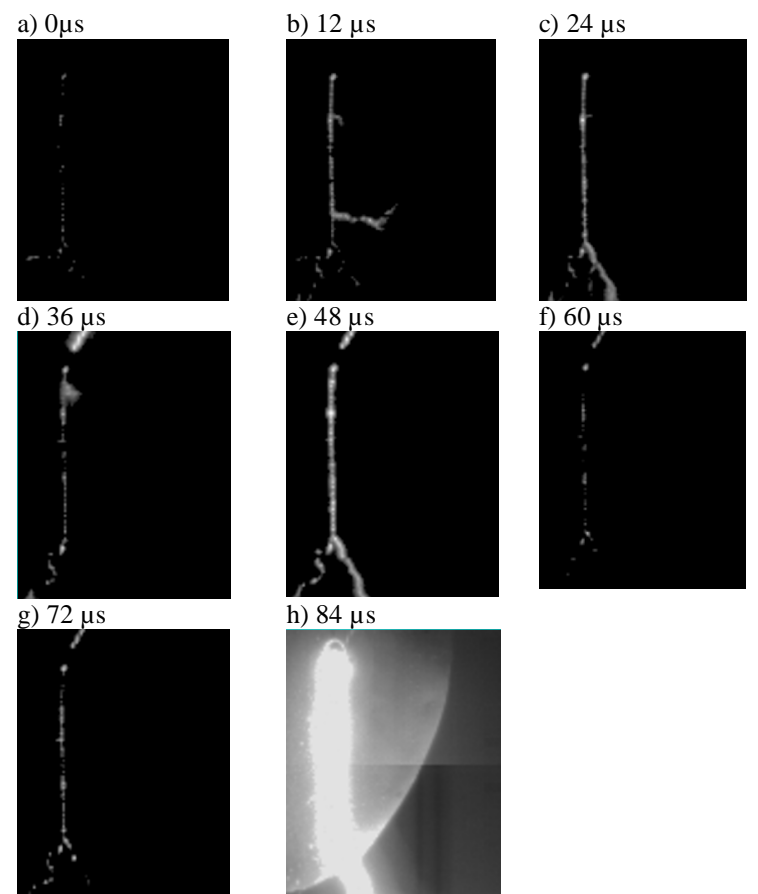

Figure 8 . Leader process in a positive breakdown of a polluted blade with diverter strips.

High-speed videos in this configuration (figure 10) show how leaders competing producing breakdowns at the boundary (figure 9a) and at the tip (figure 9b). Figure 10 shows two frames of a video. While the voltage is raising several leaders first appears from different parts of the tip (figure 10a). After several tens of microseconds (figure 10b) only two leaders rested in competition. When the blade was placed horizontal above the ground most of the discharges occurred at the boundary. For tilted positions the metallic boundary (figure 9a) and the tip were struck (figure $9 b$ ).
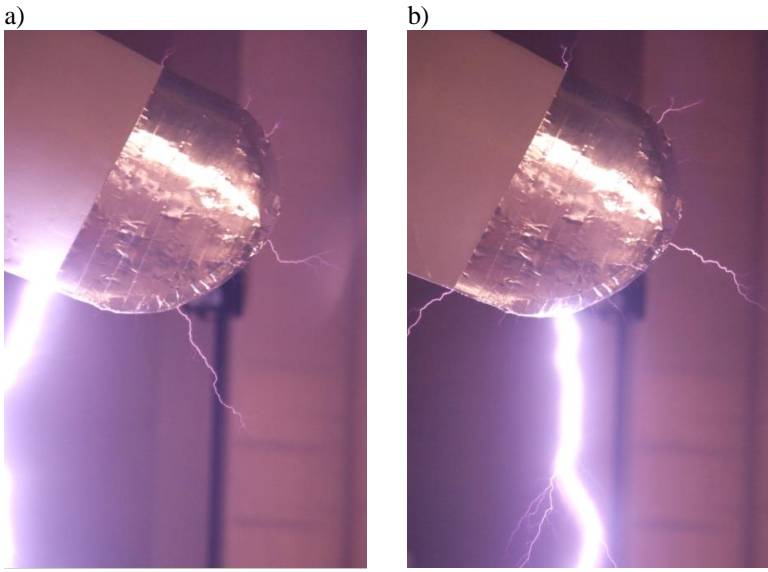

Figure 9. Breakdown of a metallic tip blade.

Results interesting observe how leaders compete in different blade tilt. The blade must be practically vertical to produce all the breakdowns to the tip instead the boundary. This suggests the importance of the conductive tip length in natural lightning.

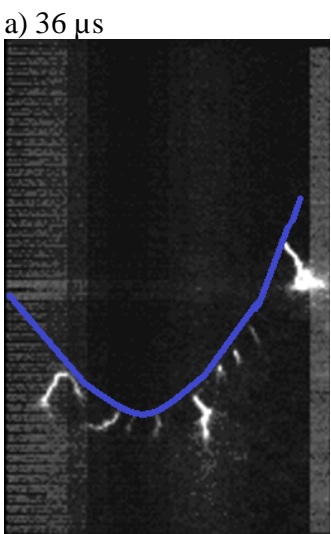

b) $96 \mu \mathrm{s}$

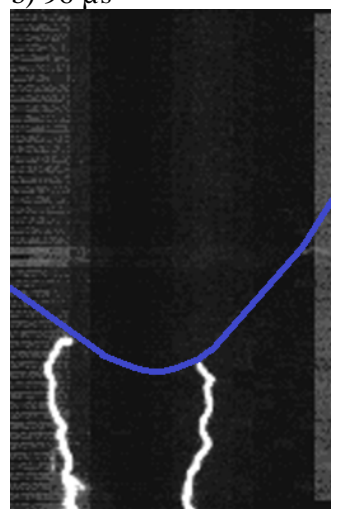

Figure 10. Two frames of high-speed video of positive voltage breakdown.

\section{CONCLUSIONS}

We present here the effects on the leader behavior produced by salt mist over the blade surface provided with a single receptor. We denoted when the blade is clean how positive leaders avoid the surface and travel direct to the ground. As the blade becomes polluted initial lateral leaders appears before the breakdown to ground. It suggests that the pollution may contribute to change the blade surface conductivity and changes the electric field in the tip area.

When in addition to the discrete tip receptors have been added diverter strips, we find also effects on the diverter behavior due to the pollution. 
The last configuration has been using a conductive tip. In this case we have seen the competition between tip leaders and leaders incepted at the shell-tip boundary. In his configuration the tilt of the blade and the length of the conductive tip result important.

The proposed tests in the IEC 61400-24 are suitable to investigate the probable points of lightning attachment by a blade. However, it is difficult to obtain a very good efficiency when simple receptors, as presented here, are employed. With this tests we would consider as possible attachment locations those where streamer/leaders appeared. The difficulty resides in the optical observations and the voltage level. The cameras and lenses have to be prepared for picturing the UV. Even a lens can perform very well in the UV, the f-stop, external lights and noise can affect the final result.

Acknowledgments. We would express our grateful to INGESCO (lightning protection company) letting us to use the high voltage laboratory. This work would not be possible without the support of the Spanish MICINN grants ESP2007-66542-C04-02 and AYA2009-14027C05-05

\section{REFERENCES}

[1] IEC TR 61400-24, "Wind Turbine Generator Systems - Part 24: Lightning Protection", 2002, [Online]. Available: http://www.iec.ch.

[2] T.S, Sorensen and many others, "The Update of IEC 61400-24 Lightning Protection of Wind Turbines", Proceedings of International Conference on Lightning Protection, 2006.

[3] J. Holboell, S.F. Madsen, M. Henriksen, K. Bertelsen, H.V. Erichsen, "Discharge phenomena in the tip area of wind turbine blades and their dependency on material and environmental parameters", Proceedings of International Conference on Lightning Protection, 2006.

[4] S. Arinaga et al., "Experimental Study on Lightning Protection Methods for Wind Turbine Blades", Proceedings of International Conference on Lightning Protection, 2006.

[5] H. Sakamoto, N. Kubo, Y. Hashimoto, I. Suzuki, Y. Ueda and M. Hanai, "Lightning Failure Protection of FRP Blades for Wind Power Generators", Proceedings of International Conference on Lightning Protection, 2006.

[6] S. Yokoyama and Y. Hongo, "Evaluation of characteristics of winter lightning and testing results related to lightning protection for wind turbines", Proceedings of International Conference on Lightning Protection, 2008.

[7] N.J. Vasa, T. Naka, S. Yokoyama, A. Wada and A. Asakawa, "Experimental study on lightning attachment manner considering various types of lightning protection measures on wind turbine blades", Proceedings of International Conference on
Lightning Protection, 2006.

[8] S.I. Sumi, H. Aichi, K. Horii, M. Yoda, M. Minami, M. Minowa, "Breakdown Test of Wind Turbine Blade for Improved Lightning Protection", Proceedings of International Conference on Lightning Protection, 2006.

[9] M. Minowa, S.I. Sumi and K. Horii, "A Study on Risk of Lightning Damages of Wind Turbine Blade by Using the Balsa-Core and Glass Fiber Reinforced Plastic Skin", Proceedings of International Conference on Lightning Protection, 2008.

[10] T. Shindo, A. Asakawa and M. Miki, "A Study of Lightning Striking Characteristics to Wind Turbines", Proceedings of International Conference on Lightning Protection, 2008. 